\title{
Leak-Resistant Rotation Seal for Vacuum Applications
}

\author{
Frank L. Howard
}

(June 6, 1963)

\begin{abstract}
A leak-resistant rotation seal for application with vacuum systems is described. The packing comprises a system of Teflon cones with deformable ridges that act as bearing surfaces.
\end{abstract}

The seal described herein was designed to convert a rotary-tube stirrer used for measurement of freezing point at $1 \mathrm{~atm}$ to one that would allow measurements at reduced pressure, approaching triple point conditions.

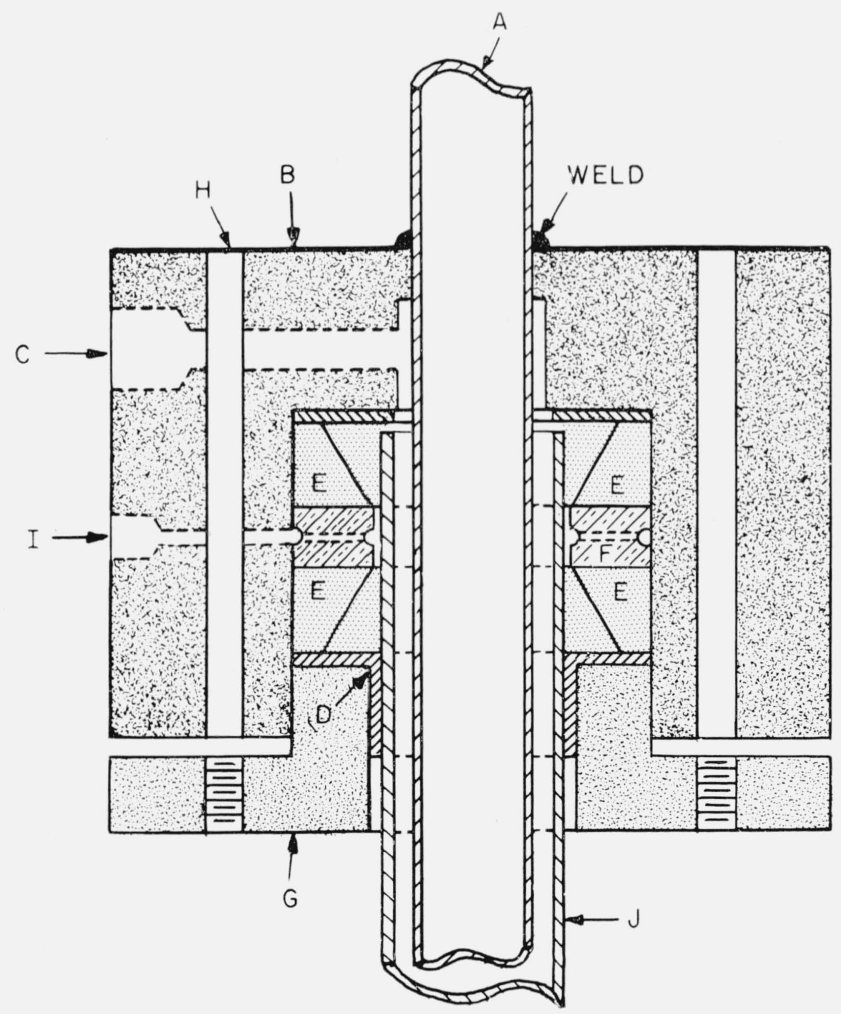

Figure 1. Sectional view of seal.

\footnotetext{
A. Thermometer well used in this application. The thermometer was attached through a standard packing gland.

B. Housing for the seal, made of stainless steel, o.d. $=2 \mathrm{in}$.

C. Connection to vacuum system.

C. Tennection to

$\mathrm{D}$, F. Packing shown in detail in figure 2

E, F. Packing shown in detail in figure 2 .

I. Connection for guard vacuum.

J. Rotating tube with polished surface on bearing area.
}

For this application it was desired that the packing material be inert, provide low friction and effectively prevent leakage. Polytetrafluoroethylene (Teflon brand) was selected for this purpose, and the packing sections were designed to partially obviate the cold flow properties of this material and to reduce the

DETAIL OF PACKING

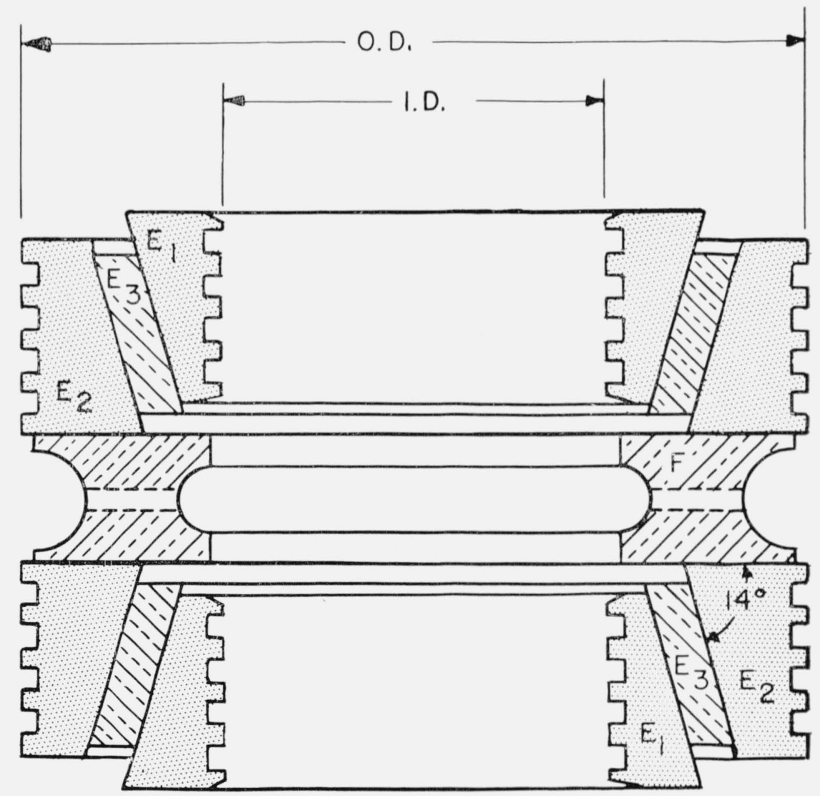

\subsection{DEEP \\ 0.040 WIDE \\ D.O20 BETWEEN SLOTS}

Figure 2. Enlarged view of packing.

$\mathrm{E}_{1}$. Inner cones of Teflon, the internal diameter is $0.010 \mathrm{in}$. smaller than outside diameter of J (fig. 1)

$\mathrm{E}_{2}$. Outer cones of teflon, similarly larger than inside diameter of housing $\mathrm{B}$ (fig, 1).

$\mathrm{E}_{3}$ Brass cone, a taper of $14^{\circ}$ was used.

F. Guard vacuum collecting ring. 
friction inherent in large bearing surfaces. The parts of the seal are illustrated in figures 1 and 2 . When the plastic packing cones are compressed vertically the small brass cones separating them cause them to tighten laterally against the rotating shaft and the outer housing. Some deformation of the protuberances between the grooves enables a tight fit.

The seal was tested with a helium mass spectrometer leak detector, while the shaft was rotated at $20 \mathrm{rpm}$. It was found that at about $5 \times 10^{-5} \mathrm{~mm} \mathrm{Hg}$ the leakage rate was less than $2 \times 10^{-9} \mathrm{~cm}^{3}$ (STP) of gas per minute. At this pressure, the guard vacuum was disconnected and no increase in pressure or in rate of leakage was noted. During $2 \mathrm{hr}$ of operation the temperature of the housing increased about $10{ }^{\circ} \mathrm{C}$.
The assistance of Herbert B. Lowey and Tully J. Pound, in making this apparatus is gratefully acknowledged. James L. Cross suggested use of the guard vacuum. 